\title{
PARTISIFASI MASYARAKAT DESA LAHAM DALAM PENGELOLAAN HUTAN DESA DI DESA LAHAM KECAMATAN LAHAM KABUPATEN MAHAKAM ULU PROVINSI KALIMANTAN TIMUR
}

\author{
Ismail Bakrie $^{1}$ dan Frederikus Paskalis Dani Purnama Luhat ${ }^{2}$ \\ ${ }^{1,2}$ Fakulltas Pertanian Universitas 17 Agustus 1945 Samarinda. \\ Jl. Ir. H. Juanda No.80 Samarinda 75124, Kalimantan Timur, Indonesia. \\ Email: bakrieis@gmail.com
}

\begin{abstract}
ABSTRAK
Partisifasi Masyarakat Desa Laham Dalam Pengelolaan Hutan Desa Di Desa Laham Kecamatan Laham Kabupaten Mahakam Ulu Provinsi Kalimantan Timur.

Keterlibatan masyarakat dalam pengelolaan hutan secara langsung sangat bermanfaat bagi pengembangan dan pelestarian hutan secara umum, khususnya Hutan Desa.

Tujuan penelitian ini adalah untuk mengetahui peran Masyarakat Desa dalam pengelolan Hutan Desa di Desa/Kampung Laham, apakah sudah sesuai dengan yang diharapkan Pemerintah atau para pemerhati kelestarian hutan.

Penelitian dilaksanakan di kawasan Hutan Desa Laham/Kampung Laham Kecamatan Laham Kabupaten Mahakam Ulu pada bulan Juni 2020 dan selesai bulan Agustus 2020, pelaksanaan penelitian dilakukan di lapangan dan lembaga-lembaga terkait yang mengurus Hutan Desa.

Hasil penelitian menunjukan bahwa masyarakat mempunyai peran sangat besar dalam pengelolaan Hutan Desa, keterlibatan masyarakat dalam pengelolaan Hutan Desa mulai dari perencanaan, pelaksanaan penanaman berbagai jenis tanaman sebagai bentuk pengayaan jenis-jenis tanaman di Hutan Desa sampai keterlibatan masyarakat dalam kegiatan perlindungan dan pemeliharaan.
\end{abstract}

Kata kunci : Desa Laham, Partisifasi, Pengelolaan hutan.

\begin{abstract}
The Participation of Laham Village Community in Village Forest Management in Laham Village, Laham District, Mahakam Ulu Regency, East Kalimantan Province.

Community involvement in forest management directly is very beneficial for the development and conservation of forests in general, especially Village Forests. The purpose of this study was to determine the role of the Village Community in managing the Village Forest in the Village/Kampung Laham, whether it was in accordance with the expectations of the Government or forest conservation observers. The research was was conducted in the Laham Village Forest / Laham Village, Laham District, Mahakam Ulu Regency in June 2020 and completed in August 2020, the research was conducted in the field in the field and related institutions that manage the Village Forest. The results of the study show that the community has a very large role in the management of the Village Forest, community involvement in the management of the Village Forest starts from planning, planting of various types of plants as a form of enrichment of plant species in the Village Forest to community involvement in protection and maintenance activities.
\end{abstract}

Key words : Participation, Forest Management, Laham Village.

\section{PENDAHULUAN}

Hutan Desa pada prinsipnya adalah Hutan Negara yang dikelola oleh masyarakat dalam organisasi administratif pedesaan yang dimanfaatkan untuk kesejahteraan masyarakat desa itu sendiri. Artinya, Hutan Desa itu bermaksud untuk 
memberikan akses kepada masyarakat setempat melalui lembaga desa dalam memanfaatkan sumberdaya hutan secara lestari dengan harapan sebagai tujuannya adalah meningkatkan kesejahteraan masyarakat setempat secara berkelanjutan. Semua aturan atau kebijakan yang telah dikeluarkan pemerintah pusat terkait pengelolaan sektor kehutanan tentu berdasarkan pengalaman-pengalaman masa lampau. Selain itu, akibat tekanan penduduk terhadap kawasan hutan adalah meningkatnya perambahan hasil hutan dan praktek illegal logging yang semakin merusak hutan alam di Indonesia.

Keterlibatan masyarakat dalam pengelolaan hutan secara langsung sangat bermanfaat bagi pengembangan dan pelestarian hutan, khususnya Hutan Desa. Hal ini akan meningkatkan pengetahuan dan pemahaman mereka akan pentingnya keberadaan hutan, bagaiman peran hutan dalam aspek ekonomi, sosial, budaya dan lingkungan (ekologis), sehingga dengan mudah akan menimbulkan cinta masyarakat pada hutan, yang pada gilirannya kelak akan mudah mengajak mereka berpartisipasi secara sukarela dalam lembaga-lembaga pengelolaan dan pelestarian hutan, khususnya Hutan Desa yang dikembangkan di desa mereka. Karena pada dasarnya, penyelenggaraan Hutan Desa bertujuan untuk meningkatkan kesejahteraan masyarakat setempat secara berkelanjutan dan menjamin kelestarian lingkungan. Karena itu pelaku utama hutan desa adalah Lembaga Desa yang dalam hal ini lembaga kemasyarakatan yang ditetapkan dengan Peraturan Desa (Perdes) secara fungsional berada dalam organisasi desa dan bertanggung jawab kepada Kepala Desa dan diarahkan menjadi Badan Usaha Milik Desa (BUMDes). Dalam pelaksanaannya, program Hutan Desa pun diarahkan sesuai prinsip-prinsipnya bahwa tidak mengubah status dan fungsi kawasan hutan dan ada keterkaitan masyarakat terhadap sumber daya hutan. Tujuan penelitian adalah untuk mengetahui peran masyarakat desa dalam pengelolaan Hutan Desa dan jenis tumbuhan yang ditanam sesuai dengan Undang-Undang Nomor 41 Tahun 1999 Tentang Kehutanan (Akhmaddhian, 2013; Supadi, 2020; Utama dan Rizana, 2020; Gunawan, 2013; Bakue, 2019; Tarigan, 2020).

\section{METODA PENELITIAN}

\subsection{Tempat dan Waktu}

Penelitian ini telah dilakukan di kawasan Hutan Desa di Desa Laham Kecamatan Laham Kabupaten Mahakam Ulu. Pada bulan Juni 2020.

\subsection{Objek Penelitian}

Objek penelitian adalah masyarakat desa di sekitar kawasan Hutan Desa di Desa Laham Kecamatan Laham Kabupaten Mahakam Ulu.

\subsection{Peralatan Penelitian}

Kuesioner (pertanyaan-pertanyaan yang akan diajukan saat melakukan penelitian), Alat tulis (untuk mencatat data), GPS (untuk menentukan lokasi kawasan Hutan Desa), Kamera (untuk pengambilan gambar).

\subsection{Jenis dan Sumber Data}

Jenis data yang digunakan dalam penelitian ini adalah data deskriptif yang berupa data primer dan sekunder.

\subsection{Pelaksanaan Penelitian}

Penelitian ini dilaksanakan dengan metode purposive sampling, yaitu salah satu tekhnik sampling non random dimana peneliti menentukan pengambilan sampel dengan cara memperhatikan ciri-ciri khusus yang sesuai dengan tujuan penelitian 
sehingga diharapkan dapat menjawab permasalahan penelitian: Menentukan lokasi kawasan hutan yang akan di teliti yaitu di kawasan Hutan Desa di Desa Laham, melihat langsung lahan dan kawasan hutan yang telah di kelola warga setempat (Warga Desa Laham).

\subsection{Pengolahan Data}

Data yang diperoleh dianalisa secara deskriptif untuk mengetahui partisifasi dan peran masyarakat dalam pengelolaan Hutan Desa Laham Kabupaten Mahakam Ulu.

\section{HASIL PENELITIAN DAN PEMBAHASAN}

3.1. Gambaran Umum Lokasi Penelitian Penelitian ini dilakukan di Hutan Desa Kampung Laham terletak di Kampung Laham Kecamatan Laham Kabupaten Mahakam Ulu Provinsi Kalimatan Timur. Kampung Laham ini berjarak $44 \mathrm{Km}$ dari ibukota Kabupaten Mahakam Ulu dengan waktu tempuh 1 Jam dengan menggunakan transpotasi sungai. Areal kerja Hutan Desa dengan batas-batas sebagai berikut : Sebelah utara Kampung Long Hurai dan Mamahak Besar, Sebelah Selatan Kampung Long Hubung dan Muara Ratah, Sebelah Timur Kampung Matalibaq, Sebelah Barat KAmpung Long Gelawang.

3.2. Keterlibatan Masyarakat Desa/Kampung Laham Dalam Peran Sertanya Mengelola Hutan Desa Pengelolaan Hutan Desa

\begin{tabular}{|c|c|c|}
\hline \multicolumn{2}{|c|}{ Berdasarkan } & Keputusan \\
\hline Menteri & LHK & Nomor: \\
\hline \multicolumn{3}{|c|}{ SK.534/Menlhk-PSKL/PKPS/ } \\
\hline PSL.0/2 & tentar & Dan \\
\hline
\end{tabular}

Lembaga Pengelola Hutan Desa Laham seluas 1.933 (seribu sembilan ratus tiga puluh tiga) Hektar pada kawasan hutan Produksi di desa Laham Kecamatan Laham Kabupaten Mahakam Ulu Provinsi Kalimantan Timur.

Kegiatan kehutanan yang akan di kembangkan di lokasi Hutan Desa adalah:

\section{Konservasi Hutan}

Konservasi merupakan kegiatan yang sangat penting dilakukan di wilayah Hutan Desa, hal ini bertujuan untuk mencegah kepunahan dari jenis-jenis flora dan fauna tertentu yang ada di wilayah tersebut, hal ini dilakukan terhadap jenis-jenis flora atau fauna yang merupakan penyusun ekosistem asli setempat (Alam, 2003).

Kegiatan konservasi dilakukan dengan melakukan pengayaan tanaman jenis asli, pengayan jenis pohon sumber pakan fauna dan apotek hidup, yaitu antara lain:

1) Pengayaaan jenis tanaman asli antar lain : Eusyderoxylon zwagery (Ulin), Shorea sp. (Meranti), Shorea laevis (Bangkirai), Shore sp. (Tengkawang), Koompassia $s p$ (Banggeris), Araucaria sp. (Arau), Dryobalanops sp. (Kapur) dan Durio sp (Durian).

2) Pengayaan jenis pohon sumber pakan fauna setempat seperti: Ficus sp. (Lunuk/Beringin), uvah, Leucaena sp. (Petai hutan), klamo, pelaq, kelimah, Macaranga $s p$. (Gelaq/Mahang).

3) Pengayaan jenis tanaman apotek hidup antara lain : Eurycoma longifolia (Pasak bumi), akar pasak bumi, Fibraurea sp. (Akar kuning), Piper sp. (Sirih merah dan sirih 
biasa) tefo kunba ( tumpang sari dengan pinang), Areca catechu (Pinang).

Kegiatan konservasi ini dilakukan mulai tahun ke-2 sampai tahun ke-10 dengan rencana kegiatan pengayaan 200 bibit per-tahun masing-masing jenis.

\section{Perlindungan dan Pengamanan Hutan}

Perlindungan dan pengamanan hutan dilakukan dengan melakukan berbagai kegiatan seperti penandaan batas dan pembagian zonasi, penanggulangan kebakaran, pencegahan kebakaran hutan dan lahan, penanggulangan pencurian kayu dan HHBK, perlindungan flora dan fauna serta upaya pencegahan longsor dan banjir.

Penandaan batas dilakukan dengan melalui kegiatan rintis dan pemasangan patok batas hutan desa, hal ini dilakukan sebagai tindakan pengamaanan areal Hutan Desa dari aksi penyerobotan lahan oleh pihakpihak yang tidak diinginkan terutama dengan lokasi yang berbatasan dengan perizinan lainnya. Penadaan batas dan pemasangan patok batas dilakukan di tahun pertama pengelolaan.

Kegiataan pemetaan dilakukan masyarakat kampung Laham dengan bantuan dan bimbingan institusi terkait seperti dinas kehutanan provinsi, balai penetapaan kawasan hutan (BPKH) serta PSKL wilayah Kalimantan. Kegiatan ini bertujuan untuk untuk memetakan lokasi hutan desa menjadi zonasi-zonasi sesuai dengan peruntukannya, kegiatan ini dilakukan di tahun pertama pengelolaan.

Kegiatan perlindungan dan pengamaanan kawasan Hutan Desa dilakukan oleh msyarakat untuk menghindari kerugian karena perambahan dan pencurian hasil hutan kayu, antara lain:

1) Membuat papan peringatan dan informasi mengenai larangan aktifitas di hutan desa (HD),

2) Pembuatan pos jaga dan pembangunan base camp, sarana prasarana pendukung di atas dibangun pada tahun pertama pengelolaan, yang dilanjutkan dengan :

Pembangunan askes jalan, Sekat bakar di lokasi Hutan Desa, di rencanakan pada akhir tahun ke-2 pengelolaan askes jalan dan sekat bakar sudah selesai dilaksanakan, Pengamanan lokasi hutan dari kebakaran dilakukan dengan pembentukkan kelompok pemadam kebakaran yang di tunjang dengan peralatan pemadaman kebakaran, Kegiatan pencegahan kebakaran hutan dan lahan melalui patrol yang dilakukan setiap bulannya, Pelaksanaan sosialisasi mengenai keberadaan Hutan Desa secara rutin setiap tahunnya kepada warga sekitar Hutan Desa kampung Laham,Patroli gabungan dengan polhut (dalam tahap penyusunan rencana), Penyuluhan setiap 6 bulan sekali.

Kegiatan pencegahan terhadap punahnya flora dan fauna di dalam Hutan Desa Laham, juga dilakukan edukasi internal Hutan Desa dibantu petugas dari Balai KSDA Provinsi Kalimantan Timur Dinas, tentang flora dan fauna yang dilindungi serta mensosialisasikan aturan mengenai satwa liar yang dilindungi (direncanakan dilakukan rutin setiap tahun). 


\section{Rencana Pemanfaatan dan Pemungutan Hasil Hutan Kayu dan Bukan Kayu}

1) Rencana pemanfaatan hasil hutan dan pengembangan hasil hutan kayu akan dilaksanakan pada lahan-lahan tidak produktif yang dibagi berdasarkan zona atau blok dengan pola tanaman campuran jenis tanaman kehutanan yang diinginkan masyarakat dan mempunyai nilai ekonomi tinggi. Pembuatan persemaian untuk alokasi lahan seluas 1.913 hektar di rencanakan 2 hektar dengan lokasi di hasung belua/hasung kayo dengan jenis bibit tanaman yaitu Sengon, sebagai tanaman konservasi dan tanaman lain berupa sumber pakan fauna/ ternak.

Berdasarkan diskusi yang dilakukan oleh masyarakat kampung Laham jenis tanaman kehutanan yang potensial dikembangkan dalam pengelolaan Hutan Desa khususnya pada daerah-daerah terbuka antara lain :

a) Jenis Sengon yang direncanakan penyiapan lahan, penanaman dan penyulaman pada tahun ke 2 dengan target sebanyak 12.500 batang dengan luasan lahan 25 Ha selama 10 tahun

b) Limbah kayu ulin (pemeliharaan terubusan).

2) Bimbingan dan arahan kepada masyarakat dari Dinas terkait untuk pengembangan dan pemanfaatan hasil hutan bukan kayu serta pemanfaatan kawasan hutan dimasa yang akan datang.

Komoditi hasil hutan bukan kayu yang dapat dikembangkan dan prospeknya baik kedepan di dalam kawasan Hutan Desa antara lain ;

a) Calamus $s p$, dari jenis rotan seltup (wai telung), rotan sega (wai hegaq) 1Ha/tahun (akan ditanam dengan 100 rumpun/tahun, dan jarak tanam $10 \times 10 \mathrm{~m}$, luas 8 ha dengan lokasi Hutan Desa Laham wilayah kelavang jidoq sampai kelabang besar serta sepanjang jalan poros).

b) Jenis daun biru/sameet, dengan rencana jumlah tanaman 1.000 batang, jarak tanam $5 \times 10 \mathrm{~m}$ (200batang/Ha) dengan luas $5 \mathrm{Ha} \quad(125$ batang/tahun).

c) Aquilaria malaccensis Lamk. (Gaharu) seluas $1 \mathrm{Ha}$ dengan jarak tanam 33 meter.

d) Dyera $s p \quad$ (Jelutung hitam) seluas $1 \mathrm{Ha}$, jumlah tanaman 100 batang dengan jarak tanam $10 \times 10$ meter.

e) Jenis bambu/bulu laan seluas 4,5 Ha dengan jumlah tanaman 400 batang, jarak tanaman $1 \times 15 \times 3.000 \mathrm{~m}$ yang dibagi dalam 2 jalur tanam.

f) Theobroma cacao (Kakao/Coklat) dengan rencana seluas $25 \mathrm{Ha}$, jumlah tanaman 15.625 
batang, jarak tanam

$4 \times 4$ meter

(dilaksanakan

kelompok tani kelavang jaya)

g) Karbon trade (penjualan karbon) dengan kegiatan pemetaan lokasi karbon trade dan penghitungan potensi karbon.

\section{Apa saja tanaman/tumbuhan yang} dapat ditanam di Hutan Desa

Jenis-jenis tanaman yang dipersiapkan untuk pengembangan Hutan Desa seluas $\pm 1.933 \mathrm{Ha}$ antara lain jenis-jenis tanaman konservasi dan pakan fauna, dengan rencana persemaian adalah 2 ha pada tahap awal berlokasi di kawasan Hutan Desa yang terketak di sungai Hasung.

Adapun jenis yang akan dikembangkan terutama jenisjenis pohon asli hutan desa dan jenis lain yang prospektif antara lain :

Jenis-jenis konservasi ada beberapa yaitu : Paraserienthes falcataria (Sengon), Shorea $s p$ (Meranti) sebagai pohon asuh, Acuilaria malaccensis Lamk. (Gaharu), Dryobalanops $s p$ (Kapur), Koompassia malaccensis (Banggeris), Eusyderoxylon zwageri (Ulin), Araucaria sp (Arau), Durio sp Durian, Shorea laevis (Bangkirai) sebagai pohon asuh, Shorea sp (Tengkawang) sebagai pohon asuh

Jenis dari pakan fauna antara lain : Ficus sp. (Lunuk/Beringin), Leucaena sp. (Pettai hutan), Shore $s p$ (Tengkawang), Macaranga $s p$ (Mahang/gelaq), Araucaria $s p$
(Arau), Duabanga sp. (Terap), Parkia sp (Belungai)

Jenis tanaman agroforestry antara lain : Eurycoma longifolia (Pasak bumi), Fibraurea sp. (Akar kuning), Piper sp (Sirih merah), Piper sp (Sirih biasa)

Bibit di peroleh dari bantuan Dinas terkait ataupun swadaya dari lembaga penglola Hutan Desa kampung Laham yang dibantu oleh masyarakat sekitar Hutan Desa (partisipasi).

\section{Pengembangan}

Jasa

\section{Lingkungan}

Masyarakat mendukung pengembangan jasa-jasa lingkungan yang nantinya dapat di kembangkan menjadi ekowisata yaitu antara lain :

1) Wisata air terjun ban kelavang

2) Camping ground ban kelavang

3) Wisata edukasi

4) Penaatan,dan perawatan ban kelavang/anak sungai kelavang

\section{Pengembangan Kelembagaan}

Masyarakat ikut berperan untuk peningkatan SDM dalam pelatihan :
1) Penyusunan
AD/ART LPHK

2) Pelatihan pemetaan partisipasif

3) Pelatihan budidaya sengon

4) Pelatihan manajemen keuangan

5) Pelatihan kerajinan rotan

6) Pelatihan pengolalan kakao

7) Pelatihan pokdarwis

8) Pelatihan pembuatan pupuk organik

9) Pelatihan memahaat 
10) Pelatihan budidaya tanaman obat tradisonal

11) Pelatihan pengolahan bahan alam

Kegiatan pelatihan dilaksanakan pada tahun pertama, kedua dan seterusnya (sesuai yang telah dijadwalkan) dengan pendamping dari PSKL (Kementrian Lingkungan Hidup dan Kehutanan ) wilayah Kalimantan.

\section{Lembaga Penglolaan Hutan \\ Desa}

Sesuai dengan ketentuan yang dikeluarkan oleh Kementrian Lingkungan dan Kehutanan, antara lain ; No.P.83/MENLHK/SETJEN/KU

M.1/ 10/2016 tanggal 25 oktober 2016 tentang perhutanan sosial, SK.534/MenhlkPSKL/PKPS/PSL.0/2/2017

tanggal 14 febuari 2017 tentang penetapan areal kerja Hutan Desa Laham seluas $1.913 \mathrm{Ha}$;

Agar ada kesepakatan yang jelas dalam pengelolaan hutan desa ini, maka Lembaga Pengelola Hutan Desa yang didukung masyarakat berinisiatif membentuk kelompok usaha perhutanan sosial, dan telah dilaksanakan pada tanggal $12 \mathrm{Mei}$ 2017 dengan Berita Acara Nomor 11/LPHD-KL/BA/V/2017

(Simangunsong dan Nababan, 2018; Kagungan et al., 2019; Yulia dan Kaskoyo, 2019). Maka terbentuk kepengurusan dalam pengelolaan Hutan Desa Lahan sebagimana di bawah ini:

Ketua

BENIDIKTUS NGERUNG

Sekretaris : MARTINUS

LASAH

Bendahara : VIKTORIUS

PARAN

\section{Monitoring dan evaluasi}

Monitoring dan evaluasi dilakukan baik secara internal maupun eksternal, monitoring dan evaluasi secara eksternal dilakukan oleh pemerintah daerah, pemerintah pusat dan pihak terkait lainnya. Khusus evaluasi pada tingkat pemerintahan pusat dilakukan oleh Balai PSKL wilayah Kalimantan setempat setiap 5 tahun berdasarkan sasaran kinerja kegiatan Hutan Desa.

Kegiatan monitoring dan evaluasi secara internal dilakukan setiap tahunnya untuk mengevaluasi proses pelaksanaan pengelolaan Hutan Desa berdasarkan rencana kerja tahunan (RKT) hutan desa kampung Laham.

Hutan Desa kampung Laham setiap tahunnya membuat laporan pelaksanaan kegiatan pengelolaan hutan desa kepada Menteri Lingkungan Hidup dan Kehutanan.

3.3. Peran Lain dari Masyarakat Dalam Pengelolaan Hutan Desa Kampung Laham

Partisifasi dan peran dari masyarakat selain yang disebutkan diatas ada beberapa adalah menyediakan tenaga membantu pengelola Hutan Desa, memotivasi masyarakat sekitar Hutan Desa untuk lebih berperan dalam pengembangan Hutan Desa, sebagai mitra yang sejajar dalam setiap pengambilan keputusan, perencanaan, dan implementasi didalam Hutan Desa, memberikan saran dan masukan bersifat konsultatif kepada pengelola dan apa saja yang menjadi kendala dalam pembangunan Hutan Desa ini, membantu pengelola dalam penanaman/pembibitan tanaman 
yang akan ditanam di lahan Hutan Desa, sebagai bagian dari lembaga adat, masyarakat melalui kepala adatnya, tetap menjaga dan melestarikan peranata-peranata hukum adat, yang di percaya sebagai hukum yang dapat mengatur keseimbangan dan keserasian hubungan manusia dengan lingkungan alam.

Sebagian besar kegiatan dimana masyarakat terlibat didalamnya dilakukan secara gotongroyong bersama lembaga-lembaga terkait, dan apa bila bibit sudah siap ditanam setiap masyarakat terkait akan datang mengambil bibit secara berkelompok, agar pembagian bibit ini secara merata. Dinas terkait biasanya menyediakan bibit Kakao (Coklat) beserta pupuk untuk kegiatan penanaman pada lahan Agroforestry.

Beberapa kendala yang sering diahadapi masyarakat dalam pengelolaan Hutan Desa antara lain sarana penunjang kegiatan pengelolaan Hutan Desa seperti :pupuk, pestisida untuk di Pembibitan dan di lapangan.

Untuk ketertiban dalam peran serta mereka ikut membangun Hutan Desa dan agar terbentuk budaya mengelola hutan yang benar dan lestari maka masyarakat di minta untuk selalu mengikuti setiap kegiatan yang di lakukan oleh Lembaga Pengelola Hutan Desa. diharapkan dengan cara ini peningkatkan ekonomi masyarakat sekitar Hutan Desa dapat terwujud. Hasil penelitian ini menunjukkan bahwa kebijakan Perhutanan Sosial, yang dalam hal ini hutan lindung Nagari Jorong Simancuang ditetapkan sebagai Hutan Desa, telah membangkitkan partisipasi warga Jorong dalam mengelola hutan nigari (Zulevi dan Adiwibowo, 2018).

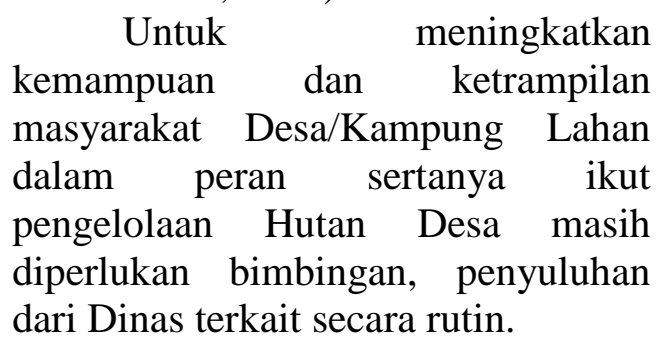

\section{KESIMPULAN}

Hasil pengamatan dilapangan dan diskusi dengan pengelola Hutan Desa maupun dengan masyarakat sekitar dapat disimpulkan bahwa : Peran masyarakat Desa Laham dalam ikut membantu pengelola Hutan Desa sangat besar, peran mereka antara lain dalam bentuk sumbangsih dalam memobilisasi bahan dan peralatan untuk memperlancar kegiatan perancanaan, membantu dilahan pembibitan, membantu proses penanaman dan ikut serta dalam kegiatan perlindungan dan pengamanan Hutan Desa.

Adapun beberapa jenis tanaman yang telah terealisasi penanamannya yaitu Paraserienthes falcataria (Sengon) di lahan-lahan Konservasi dan Jenis Theobroma cacao (Kakao atau Coklat) di Kebun-kebun Agroforestry. Jenis tanaman yang telah di rencanakan untuk penanamn dalam rencana kerja pengelolaan Hutan Desa antara lain beberapa jenis Kayu Hutan jenis asli seperti Shorea sp (Meranti-merantian), Aquilaria malaccensis (Gaharu), Dryobalanops sp (Kapur), Koompassia malaccensis (Banggeris), Eusyderxylon zwageri (Ulin), Araucaria sp. (Arau), Durio sp. (Durian), Shore laevis (Bangkirai), Shorea sp. (Tengkawang), dan jenis-jenis kayu pakan ternak dan jenis campuran untuk lahan agroforestry. 


\section{DAFTAR PUSTAKA}

\begin{tabular}{ccr}
$\begin{array}{c}\text { Akhmaddhian, } \\
\text { pemerintah }\end{array}$ & (2013). & Peran \\
mewujudkan & hutan & konservasi \\
berdasarkan & \multicolumn{2}{c}{ Undang-Undang } \\
Nomor 41 Tahun 1999 tentang \\
Kehutanan & (Studi di & Kabupaten \\
Kuningan). & Jurnal & Dinamika \\
Hukum, 13(3), 446-456. &
\end{tabular}

Alam, S. (2003). Mewujudkan hutan desa sebagai alternatif pengelolaan hutan berbasis masyarakat. Makalah Lokakarya Hutan Desa Universitas Hasanuddin. Makassar.

BakueAKUE, M. S. (2019). Analisis Putusan Mahkamah Konstitusi Nomor. 35/PUU-X/2012 Tentang pengujian Undang-Undang Nomor 41 Tahun 1999 Tentang Kehutanan Dalam Perspektif Perlindungan Masyarakat Hukum Adat. Skripsi, 1(271412052).

Gunawan, A. (2013). Analisis Yuridis Terhadap Alih Fungsi Hutan Lindung Dikaitkan Dengan Undang-Undang Nomor 41 Tahun 1999 Tentang Kehutanan Juncto Undang-Undang Nomor 32 Tahun 2009 Tentang Perlindungan Dan Pengelolaan Lingkungan Hidup (Doctoral dissertation, Universitas Komputer Indonesia).

Indonesia, P. R. (1999). Undang Undang No. 41 Tahun 1999 Tentang:

Kehutanan. Sekretariat Negara. Jakarta.

Kagungan, D., Neta, Y., dan Kaskoyo, H. (2019). MEMBANGUN

KEMANDIRIAN

MASYARAKAT TANI HUTAN

KEMASYARAKATAN

MELALUI PENGUATAN PERAN STAKEHOLDERS

DALAM PEMANFAATAN
KEMASYARAKATAN.

PROSIDING SEFILA, 103-112.

Kementerian Lingkungan Hidup dan

Kehutanan. (2016).

P.83/Menlhk/Setjen/Kum.1/

10/2016 tanggal 25 oktober 2016

Tentang Perhutanan Sosial.

Keputusan Menteri Lingkungan Hidup. (2017). Nomor: SK.534/MenlhkPSKL/PKPS/ PSL.0/2/2017,

Tentang Pemberian Hak Pengelolan Hutan Desa kepada Lembaga Pengelola Hutan Desa Laham.

Keputusan Menteri Lingkungan Hidup. (2017). Tentang rencana pengelolaan Hutan Desa (RPHD) Desa Laham periode 2017 sampai 2026.

Peraturan Menteri Kehutanan. (2008). Permenhut Nomor : P.49/MenhutII/2008. (2008). Tentang Hutan Desa, yang di tetapkan pada tanggal 28 Agustus 2018.

Simangungsong, M., dan Nababan, R. (2018). TINJAUAN YURIDIS PERLINDUNGAN HUKUM PELAKU USAHA KELOMPOK TANI HUTAN GAPOKTAN KARYA BERSAMA DI DESA PANRIBUAN (BERDASARKAN PERATURAN MENTERI LINGKUNGAN HIDUP DAN KEHUTANAN REPUBLIK INDONESIA NOMOR P. 83/MENLHK/SETJEN/KUM. 1/10/2016 TENTANG PERHUTANAN SOSIAL. Jurnal Hukum PATIK, 7(3), 202-216.

Supadi, S. (2020). IMPLEMENTASI UU NO. 41 TAHUN 1999 TENTANG KEHUTANAN (Penegakan Hukum Pada Tahap Penyidikan Terhadap Kasus Illegal Logging Di Polres Wonogiri). Dinamika Hukum, 6(1). 
Tarigan, A. (2020). TINJAUAN YURIDIS PERLINDUNGAN HUKUM PELAKU USAHA KELOMPOK TANI HUTAN GAPOKTAN KARYA BERSAMA DI DESA PANRIBUAN (BERDASARKAN PERATURAN MENTERI LINGKUNGAN HIDUP DAN KEHUTANAN REPUBLIK INDONESIA NOMORP.

83/MENLHK/SETJEN/KUM. $1 / 10 / 2016$ TENTANG PERHUTANAN SOSIAL).

Utama, A. S., \& Rizana, R. (2020). Penegakan Hukum Terhadap Kebakaran Hutan Di Kabupaten Pelalawan Provinsi Riau Berdasarkan Undang-Undang Nomor 41 Tahun 1999 Tentang
Kehutanan. Jurnal Selat, 8(1), 108120.

Yulia Neta, Y., \& Kaskoyo, H. (2019). MEMBANGUN KEMANDIRIAN MASYARAKAT TANI HUTAN KEMASYARAKATAN MELALUI PENGUATAN PERAN STAKEHOLDERS DALAM PEMANFAATAN HUTAN KEMASYARAKATAN. In Prosiding Seminar Nasional FISIP UNILA 3.

Zulevi, X. F., \& Adiwibowo, S. (2018). Pengaruh Partisipasi dalam Pengelolaan Hutan Nagari Simancuang terhadap Tingkat Kesejahteraan Masyarakat. Jurnal Sains Komunikasi dan Pengembangan Masyarakat [JSKPM], 2(1), 13-28. 